\title{
El aporte de la enseñanza de la historia reciente en Chile: Disensos y consensos desde la transición política al siglo XXI
}

\author{
The contribution of teaching recent history in Chile: dissents and consensus from the politi- \\ cal transition to XXI century \\ A contribuição do ensino da história recente do Chile: dissidência e consenso da \\ transição política a seculo XXI
}

\author{
Patricio Rivera $O .^{\mathrm{a}}$ y Carlos Mondaca . $^{\mathrm{b}}$ \\ aDepartamento de Educación Universidad Arturo Prat. Iquique - Chile. Correo electrónico patririv@unap.cl. \\ Telf.: 56-57-394209. \\ bDepartamento de Educación Universidad de Tarapacá. Arica - Chile. Correo electrónico cemondacart@uta.cl
}

\section{RESUMEN}

En este artículo proponemos estrategias educativas que permitan a los profesores enseñar la Historia reciente. Para esto se describe el rol del período político de la transición a la democracia en Chile y se analiza la intervención institucional del Ministerio de Educación en el diseño de los textos de estudios. Específicamente, comparamos los matices educativos propuestos por estos textos para tratar temáticas contemporáneas de la historia nacional, determinando posibles relaciones entre la didáctica de los textos y posibles sesgos en las unidades pedagógicas de esta etapa histórica, lo que hace necesario la necesidad de rescatar la memoria histórica para enseñar los hechos a través de miradas nuevas que centren la enseñanza en los Valores y los Derechos Humanos con el debido respeto individual y colectivo a la Tolerancia y a la Vida.

Palabras clave: didáctica de la historia, historia reciente, memoria, olvido, Chile.

\begin{abstract}
In this paper we propose strategies that enable teachers to teach recent history; in order to do such task; the role of the political period of transition to democracy in Chile is described, analyzing the institutional intervention of the Ministry of Education in the design of textbooks used in the classroom. Specifically, we compare the educational nuances offered by these texts to address contemporary issues of national history, determining possible links between the teaching of the texts and possible biases in the teaching units of this historical period, which enhances as essential the need to rescue the historical memory to teach issues through new perspectives focusing the teaching of values and human rights with due regard to individual and collective Tolerance and Life.
\end{abstract}

Key words: teaching of history, recent history, memory, forgetfulness, Chile.

\section{RESUMO}

Propõem-se estratégias educativas que permitam aos professores ensinar História recente; para isso, descreve-se o papel do período político de transição para a democracia no Chile, analisando a intervenção institucional do Ministério da Educação na composição dos textos para estudos. Especificamente, comparam-se as nuances educativas propostas por tais textos para tratar de temáticas contemporâneas da história nacional, determinando possíveis ligações entre a didática dos textos e possíveis rumos tomados nas unidades de ensino de este período histórico, o que requer o necessário resgate da memória histórica para ensinar os feitos por meio de novos olhares que centrem o ensino em Valores e Direitos Humanos com o devido respeito individual e coletivo à Tolerância e à Vida.

Palavras chave: ensino de história, história recente, memória, esquecimento, Chile. 


\title{
1. LA PUGNA ENTRE LA MEMORIA, EL OLVIDOY EL QUERER OLVIDAR
}

...La memoria despierta es contradictoria, como nosotros; nunca está
quieta, y con nosotros cambia. No nació para ancla. Tiene, más bien
puerto de partida, no de llegada. Ella no reniega de la nostalgia; pero
prefiere la esperanza, su peligro, su intemperie. Creyeron los griegos que
la memoria es hermana del tiempo y de la mar, y no se equivocaron...

Eduardo Galeano (1998: 217)

\begin{abstract}
¿Valdría la pena que los jóvenes estudiaran historia? Esta es la pregunta que hace Nietzsche (1945) en su emplazamiento a esta disciplina. Señala, además, el filósofo alemán, que el recordar y el olvidar son necesarios para que la luz alterne con la oscuridad y así generar un sentimiento que se manifieste de forma histórica (el recuerdo) y otras de forma ahistóricas (el olvido); con ello, la historia sería una vivencia entre el recuerdo y
\end{abstract} el olvido y una propuesta crítica frente al querer olvidar.

En todas las sociedades humanas ambas dimensiones se hacen presentes y son ineludibles para el desarrollo de sujetos, individuos o colectivos, sin embargo, no puede suceder que el olvido supere a la memoria, porque el olvido lleva a lo ahistórico. Entonces, el ejercicio de la historia es la única alternativa para sistematizar la memoria y recurrir a esta para superar el olvido y adquirir una mirada crítica frente al querer olvidar, que se ha convertido en una tendencia propia de los estudios en historia reciente y que niega la posibilidad de un desarrollo comprensivo en la educación actual, dado que trae a colación sensibilidades próximas muy contingentes para la sociedad actual.

Respecto a la construcción de la memoria y el olvido en nuestras aulas, esta se hace en áreas sensibles a la "esfera pública", como fue la inserción de temáticas de la historia reciente en los materiales escolares durante el proceso de transición a la democracia pactada en Chile. Estos se construyeron sobre la base de criterios que permitían ciertos consensos en la textura del documento a leer por los escolares, quienes serían los depositarios de esta historia; estos consensos omitieron el disenso y permitieron los acuerdos políticos y, por esta razón, la memoria fue y es filtrada para hacerla unitaria y homogénea. Entre otras cosas, esta tendencia responde a la idea de reconstrucción frente a la de destrucción dejada en Chile por la dictadura militar. Tal como señala el historiador francés Georges Dúby (1988: 63): "Efectivamente, la memoria y la historia en la medida en que está construida sobre jirones de memoria, son obligatoriamente selectivas".

Por el contrario, una mirada crítica tiene por objetivo sumar memorias para reconstruir la convivencia perdida y lograr la paz social y solidez que asegure la democracia después de largos años de dictadura; sin embargo, en nuestro país esta sumatoria de memorias de unos y de otros hizo que la historia se negociara en consensos que entregó pisos o nichos al olvido, tal como señalaba Nietzsche en su equilibrio de recuerdo y olvido y como lo plantea el historiador Eric Hobsbawm, al señalar respecto al olvido que: "Olvidar, incluso interpretar mal la historia, es un factor esencial en la formación de una nación, motivo por el cual el progreso de los estudios históricos es a menudo un peligro para la nacionalidad" (Hobsbawm, 2002: 270).

Tomar aspectos de la historia reciente en Europa sobre las características de traumas colectivos, nacionales o hasta mundiales, como fue el caso del holocausto judío, puede servir como marco teórico de referencia al historiar regímenes dictatoriales como el de Augusto Pinochet. En este sentido, el filósofo y cientista social Jurgen Habermas (2011) 
señala, respecto a Alemania, que la idea fuerza que fundó Europa después del período fascista fue la integración de Alemania a la comunidad internacional en base a los valores de democracia y libertad, como una manera de superar, no olvidar, el pasado totalitario.

Entonces, el pasado debe ser constantemente recuperado y aún rescatado del olvido para construir o reconstruir el presente, teniendo en cuenta que la dictadura en Chile elaboró discursos oficiales y una única historia oficial ${ }^{1}$ que no reflejó la realidad de los "otros", es decir, los derrotados, los republicanos, los exiliados, los torturados, los relegados, los clandestinos, los detenidos desaparecidos, los "upelientos". ${ }^{2}$ Es por ello que ante esta idea de recuperación de la historia, Alain Touraine (1995) señala precisamente lo anterior: la modernidad, por tanto, el individuo, debe estar en una permanente actitud crítica, constructiva, analítica, a la par con la evolución de los acontecimientos.

Eso es mantener la memoria y derrotar las fuerzas que se empeñan en destruir lo logrado. Vivir sin memoria es peligro de retroceso, vivir con memoria es ser moderno, crítico y consciente; negar la memoria es doblegarse al sopor y la mentira. Tener presente la memoria es tener presente al ser humano, mientras que, para alienarlo, habría que olvidarlo.

La enseñanza de la historia reciente en Chile ha sido omitida desde la época de la dictadura militar hasta la innovación curricular llevada a cabo por la reforma educativa en 1997. Precisamente a partir de ese año se comienza a estudiar la forma de enseñar educativamente una "Historia Oficial" desde la esfera ministerial. ${ }^{3}$ Sin embargo, esta iniciativa se concreta recién con Textos de Estudio 4 en el año 2002, mas, los profesores del Subsector ${ }^{5}$ de Historia y Ciencias Sociales habían comenzado desde variadas ópticas o prismas individuales, colectivos o corporativos, el trabajo práctico en aulas escolares de los sucesos del Golpe de Estado y la Unidad Popular. Respecto a esta práctica, muchas veces estas unidades didácticas no eran completadas por cobertura de tiempo, voluntarismo individual o institucional y aún por "comodidad neutra".

Actualmente, estas temáticas son llevadas a clases prácticas y guiadas principalmente por los Textos de Estudio, como material de apoyo didáctico. El Golpe es abordado desde una perspectiva episódica y secuencial desde 1950 hasta 1973, entendida como

$\overline{1}$ En el caso Chileno, el llamado "Libro Blanco", publicado por la Junta Militar de Gobierno, y el "Manual de Historia de Chile", de Francisco Frías Valenzuela, editado en la época y en uso escolar hasta hoy, forman parte de esos discursos oficiales que omitieron los horrores de la dictadura.

2 Calificativo dado en Chile a los seguidores o militantes de la Unidad Popular por su sigla UP, alianza de partidos de centro izquierda e izquierda que lleva al poder a Salvador Allende Gossens en 1970.

3 Hacia 1999, surge una discusión teórica respecto a las formas de enseñar la Historia Reciente a los estudiantes primarios y secundarios; esta polémica continua en el campo de la negociación política y retrasa los Planes y Textos de Estudio de Segundo Año Medio hasta el año 2002. Hacia mayo del año 2000 es enviada una carta al Diario El Mercurio, firmada por una veintena de destacados historiadores rechazando la manipulación y presión que hacían sectores de la derecha chilena.

$4 \quad$ Los Textos de Estudio de las escuelas chilenas corresponden a la Editorial Mare Nostrum. El texto Historia y Ciencias Sociales $2^{\circ}$ Medio (2002) de Liliam Almeyda, Pedro Milos y Pablo Whipple, desde el año 2002 es sometido a un proceso de elegibilidad por parte de los docentes de Historia y Ciencias Sociales de todo Chile, sin embargo, desde esa fecha que no se entregan resultados públicos de tal proceso por parte del Ministerio de Educación en Chile.

5 La Reforma Educativa en 1997 señala un cambio de nomenclatura en las tradicionales conceptualizaciones de asignaturas y otorga a estas el nombre de subsectores. 
un período de avance social que conduce al quiebre democrático en 1973, sin embargo, la perspectiva educativa que guía el texto y los Planes y Programas lleva a construir una opinión individual del alumno respecto a los sucesos elaborando, mediante las actividades didácticas que reconstruyen los hechos.

El ejercicio de la memoria histórica y su recreación para un ejercicio práctico de la docencia de la Historia Reciente, sobre todo del proceso de la Unidad Popular y de la dictadura, es mínimamente desarrollado. Por ende, urge enseñar una historia aún en construcción que necesariamente obedece a ciertas memorias sueltas, ${ }^{6}$ escritas u orales que necesitan enlazarse y que, a través del aula escolar, podemos hacerlas vivas en torno a recuerdos de hechos locales y regionales que permitan comprender una realidad pasada y dolorosa, que no solo forme al alumno chileno como ente de instrucción, sino que rescate en su valor social e histórico su potencia como sujeto actor o agente social al protagonizar y transformar la historia.

La propuesta de este artículo es entregar estrategias educativas que permitan en la práctica a los docentes de enseñanza básica y media enseñar una historia que para los mismos docentes es difícil de presentar por la intervención institucional o familiar ${ }^{7}$ que influencia las conductas de entrada o estrategias motivacionales a las unidades didácticas que enfrentan en esta etapa histórica, debido a la persistencia de memorias sueltas, el olvido generalizado o el autoritarismo familiar, político o social. En este sentido, la iniciativa es enseñar los hechos a través de miradas nuevas que centren la enseñanza en los Valores y los Derechos Humanos con el debido respeto individual y colectivo a la Tolerancia y a la Vida.

El docente debe considerar indicadores que permitan definir su rol como co-compilador de historias y memorias que los alumnos recopilarán en sus variadas fuentes, sin embargo, este diseño debe ser orientado de acuerdo al Eje central que señale el fin de una historia de enfrentamiento y permita equilibrar la lucha de memorias aún presentes. A modo de referencia ilustrativa, en España es el comentario del portavoz del Partido Popular Luis de Grandez, frente a un homenaje del Parlamento hispano a las víctimas del franquismo (El País, 2/11/2003) el que se traduce en un escollo al avance del progreso moderno, es decir, de la crítica, instrumento de la modernidad.

Es por ello que se hace necesaria la construcción, a través de los textos de estudio y desde la práctica pedagógica cotidiana, de un Nunca Más con respecto a las variadas opiniones de diversos sectores políticos, sociales y culturales que condenen las violaciones a los Derechos Humanos en la época de la Dictadura militar a través de medios didácticos que logren aprendizajes significativos y prácticos en el sujeto. Así, el alumno elabora un marco teórico humanista que distingue entre la crimen y la justicia, sin la timidez neutra que construye en el sujeto la relatividad de los hechos y abre puertas a la justificación violenta.

La Memoria suelta y la interacción con otras memorias conducen a una memoria colectiva capaz de entregarnos una visión histórica. Véase Stern (2000).

$7 \quad$ El Colegio de Profesores de Chile y las Redes Pedagógicas de Profesores de Historia y Ciencias Sociales (organizaciones docentes de base) han señalado que existen numerosas intervenciones de Directivos, Sostenedores y Apoderados de los colegios que obstaculizan los contenidos históricos del período 1970 a 1973 con un claro sesgo ideológico conservador o de tendencias de derecha. Véase también Diario El Metropolitano $(12 / 09 / 1999)$ 
Por lo tanto, la pretendida objetividad histórica tradicional debe retroceder ante el avance de la memoria con su respectiva carga subjetiva, que conduce a un conocimiento del acontecimiento a luz del aprendizaje dialógico, basado en la experiencia. Por eso es importante el rescate del testimonio de los actores sociales; resulta "liberador", a decir de Bourdieu (2002), de su propio sujeto, restaurar su valor histórico, su verdad mediante el diálogo intersubjetivo que logra situar empáticamente al alumno del Aquí al Allá, de la fuente o del pasado en la comprensión de la historia.

\section{LOS TEXTOS DE ESTUDIO EN CHILE: GOBIERNO MILITAR Y LA TRANSICIÓN A LA DEMOCRACIA}

Chile es un país unitario y tiene un solo texto de estudio para toda la educación secundaria, por programa educativo, basado en el Decreto 220, señalado en los cambios curriculares. Durante la administración del Presidente Eduardo Frei Ruiz Tagle, se inicia un intenso debate partidista en torno a los contenidos y a la comisión de historiadores, seleccionados para redactar el texto, principalmente. Genera inquietud la forma de tratar la época de la dictadura militar y las causas del golpe de estado en 1973. Esta discusión entrampa la edición que demora desde 1997 al 2001 en publicarse. El texto de Historia y Ciencias Sociales (2002) para $2^{\circ}$ Medio dedica 13 páginas para la transición y sintetiza el golpe de estado, las violaciones a los derechos humanos, la modernización de la economía o "neoliberalismo" y la llegada de la democracia a través de imágenes y de una muestra de variados puntos de vista de historiadores, militares e Iglesia Católica.

Resulta interesante que el texto incluya en su análisis interpretaciones históricas de la transición a la democracia como tema escolar y que este sea desarrollado como concepto de aprendizaje con artículos del periodista Ascanio Carvallo (1992), del ex Secretario General del Partido Comunista de Chile, Luis Corvalán (1997) y del ex Ministro del Interior del General Pinochet, Sergio Fernández (1994), que resumían en conjunto diferentes prismas complementarios entre sí, a la vez que se incluía variadas actividades de aprendizaje para cada sección del capítulo que abordaba no sólo aspectos políticos, sino también económicos, deportivos y culturales. Sin embargo, este texto presenta oportunidades para la reflexión y valoración del alumno de la democracia, insertando a la transición misma, a través de preguntas en las actividades de aprendizaje didáctico como lo ejemplifica la siguiente actividad:

\footnotetext{
"Actividad

Los años posteriores al autoritarismo han estado marcados por el esfuerzo de los distintos sectores políticos de transitar hacia un régimen democrático. ¿Qué quiere decir esto?

*Explica el significado que se da al concepto de "transición" en cada uno de los textos leídos. *Clasifica las razones que aparecen en los textos para sostener que la transición es un período cerrado o abierto.

* Con un grupo de compañeros, elaboren una lista de las condiciones que ustedes creen necesarias para considerar cerrado el proceso de transición.

*En diarios y revistas, busquen imágenes que les permitan graficar las complejidades del paso del autoritarismo a un régimen democrático. Usen su imaginación y compongan un collage que represente los distintos momentos del proceso de transición.
} 
*"Juicio a la transición": busquen información y preparen argumentos para evaluar las fortalezas y debilidades del proceso político vivido. Redacten un ensayo colectivamente para explicar los fundamentos de su juicio.

* ¿Cuáles son, para ustedes, las tareas políticas que todavía están pendientes para consolidar un régimen democrático?” (2002: 247).

Aunque las preguntas planteadas por el texto de estudio permiten rescatar el papel de sujeto social en el alumno y aprender la historia desde la historia, estos deberes o tareas escolares en que el alumno generalmente recurre a sus padres o abuelos, genera una "bola de nieve" de conocimientos y saberes académicos y populares, vivencias y verdades individuales sesgadas; es decir, esta actividad no permite que el alumno se aproxime a la historia para abrir un diálogo y una interacción familiar y social con sus pares, hogares o maestros y genere una intersubjetividad en el conocimiento de la historia y de su aplicación educativa que permita una empatía, para traspasar el velo del tiempo que lo aleja de algo "pasado", pero presente a la vez en la televisión, noticias o mitos orales e incluso escritos. De esta forma, no explica el porqué del dolor o la pérdida, no solo de la democracia, sino de la convivencia y la confianza social y política nacional.

En un aspecto metodológico, no se potencia efectivamente una investigación-acción que, en conjunto y mediante la discusión, permita que el sujeto, primero despierte y se haga participe de la historia; y, a partir de eso, comience su juicio a la transición, describiendo los conceptos, para así llegar a analizar o interpretar el proceso y elaborar una síntesis colectiva o individual en clases; puesto que, en la práctica, el disenso lleva también a formas dialécticas del conocimiento. Sin embargo, esta estrategia debe contar con el apoyo de la voluntad docente, institucional y directiva de las unidades educativas que supere la "comodidad neutra" que continúa con los traumas objetivistas de la historia.

\section{APRENDAMOS ÉL NUNCA MÁS: A RECUPERAR NUESTRA MEMORIA HISTÓRICA}

En el ejercicio de la memoria histórica y su recreación para un ejercicio práctico de la docencia de la Historia Reciente, sobre todo del proceso de la Unidad Popular, aparece el problema de enseñar una historia aún en construcción y que necesariamente obedece a ciertas memorias que necesitan enlazarse; sin embargo, a través del aula escolar podemos hacerlas vivas en torno a recuerdos de hechos locales y regionales que permitan comprender una realidad pasada y dolorosa que no solo forme al alumno como ente de instrucción de simple reiterador de procesos de fechas, nombres y datos, sino que rescate, en su valor social e histórico, valorando el hecho y reconstruyéndolo en su potencia, como sujeto actor o agente social al protagonizar y aún transformar la historia desde la ciudadanía participativa.

\subsection{INDICADORES DE METODOLÓGICOS}

El docente debe desarrollar un espacio para la reflexión y el análisis de los hechos, situando la descripción tempo-espacial al inicio de la unidad. En este sentido, se propone que el docente puede considerar los siguientes aspectos: 
- Intersubjetividad: Necesaria para la situación reflexiva del alumno, sobre todo apuntada a la comprensión de los hechos.

- La Actualización del Discurso: Los contenidos a desarrollar deben estar actualizados a las últimas investigaciones realizadas del tema

- El Saber: La valoración del saber popular. La memoria histórica debe ser considerada tomando en cuenta a los actores de los hechos y rescatando su testimonio.

- El Lenguaje: El docente puede desarrollar un estilo particular de su clase, utilizando un Habla que se codifique con el alumno que necesariamente debe adaptarse a los diferentes contextos socioculturales de cada unidad educativa o aun a nivel de aula o alumno.

- El Contexto: El ser pretexto, es decir, tomando la actualidad o el problema no resuelto para explicar el pasado. En el área escolar de las Ciencias Sociales existen diversas dudas, no solo de la época de la Unidad Popular, sino del contexto actual, y estas pueden ser aclaradas por este método.

- El Diálogo: La táctica para enfrentar la clase y desarrollarla con lineamientos motivacionales y de interés para el alumnado debe ser abordada por un diálogo que lúdicamente y con desafíos impulse la participación estudiantil.

- El Disenso frente al Consenso: Actualmente existe una sensación del acuerdo macro, gestado por los poderes formales y fácticos que han dejado de lado a los movimientos sociales de la discusión de temas como los Derechos Humanos. Es por ello que el desafío dialógico debe invitar al disenso, denunciando al consenso como Olvido contrario al Nunca Más; así, la reflexión constante supera la inercia del diálogo y recrean escenarios para debatir el tema de la Unidad Popular, el Golpe de Estado y la Dictadura Militar.

- Aprendizaje Social y Colectivo: En la medida que el diálogo invita a la conversación colectiva, este se hace social y participante, vinculando a todos los sujetos de la unidad didáctica. El docente debe valorar el saber popular que tiene incorporado el sujeto y nutrirse entre todos de las diversas fuentes y, sobre todo, de la interpretación valórica de los hechos que conducen a acordar que hechos de Lesa Humanidad no deben repetirse en la historia.

- El Sujeto-Alumno de la Historia: En la medida que valoramos al alumno como sujeto de aprendizaje, podemos intentar generar una transformación social en la educación al modificarse la estructura tradicional y superficialmente analítica que existe en los Planes y Programas educativos. El alumno se sentirá parte de la historia si logramos situarlo en el contexto regional o local y conectamos los conflictos de la misma con su vida cotidiana.

\subsection{ACTIVIDADES Y EVALUACIÓN: NEUTRALIDAD ACADÉMICA Y EL PROYECTO SOCIAL}

En la actualidad educativa que vivimos, debemos reinventar las estrategias para el rescate del sujeto y postular nuevas formas de rearticular el tejido social, no solo en su gestación sino que también en su dirección. Para ello es de vital importancia el rol docente, a través del currículum oculto que oralmente trasmitimos y que debe ser inspirado por un compromiso social que recupere el papel de sujeto reflexivo y transformador de la Historia, activando la pereza e incluso el miedo de la Comodidad Neutra (el Pacifismo social), que aparece en muchos docentes al abordar metodológicamente el estudio de la 
historia reciente desde la óptica descriptiva y mínimamente interpretativa. Es preciso entregar el paso a la innovación pedagógica y superar la comodidad neutra mediante la socializaciónde la propuesta, sus resultados y logros.

Así, es necesario la articulación de la Red y la Trenza de profesores, alumnos o talleres educativos que unen o proponen y que agrupa al alumno y al docente en actividades comunes, escolares, sociales, políticas y culturales. Respecto a la práctica de aula, la Didáctica podría señalar algunas actividades:

- Rescatar el Cabildo: Recuperando el valor a la Voz, la disidencia y la opinión. Se establecen Foros de temáticas diversas al aire libre o en patios o pasillos.

- Ayudantías y Tutorías: La red de Monitores, como Agentes de aprendizaje, se agrupan en Talleres.

- Investigación-Acción-Participación: Generar la conducción del alumno en su rescate activo del aprendizaje a través de fórmulas de investigación social (entrevista, encuesta, observación participante).

- El Escenario Lúdico: Recreando la Historia a través de dramaturgia, diaporamas, documentales, exposiciones, concursos, música, pintura, murales, etc. que inviten a formular una nueva propuesta del tema y para que Nunca Más en Chile vivamos los profesores y alumnos con el fusil en lugar del lápiz.

- El rescate de la memoria histórica desde el barrio a lo local inmerso en lo nacional de la historia reciente.

\section{COMENTARIOS FINALES}

Esta didáctica es el impulso que tiene el trabajo con fuentes históricas para los estudiantes, principalmente de educación secundaria y básica en colegios de la región Tarapacá, que invitarán a una nueva dimensión, dado que el estudiante recibe una amplia cobertura de contenidos, imágenes simbólicos y monumentos oficiales, sin embargo, en este caso podrá conocer otras miradas, más directas de la historia reciente y. si estas son sociales, habrá otra forma de entender la historia y ese entendimiento llevará a que conozca la memoria.

La innovación en esta didáctica está en una formación temprana de los estudiantes de Pedagogía en Historia en el trabajo con fuentes de información, es decir, que adquieran la metodología de la investigación histórica con toda el rigor disciplinario y la transfieran a la pedagogía.

Entonces, el profesor de Historia, que no tiene las capacidades para orientar a los alumnos en el trabajo con fuentes (escritas, orales, arqueológicas, patrimoniales, iconográficas, audiovisuales), sin un mínimo de información histórica y contextual sobre el tema, en papel impreso o en red, sin una formación disciplinaria a través de una metodología de la especialidad de enseñanza de la historia o didáctica específica de la historia, no será capaz de crear una sinergia entre la historia y la pedagogía ni desarrollar la propuesta de una alianza didáctico-historiográfica, necesaria para enfrentar el cambio de paradigma.

El proceso iniciado, situado el campo de estudio en este caso de la historia reciente y el contexto de los estudiantes, es decir, de la regiones en que están situados, permitirá el aprendizaje del estudiante por sí mismo, inserto en un laboratorio de la Historia o Taller de Historia y en condiciones de manejar fuentes semejantes a las utilizadas por los 
Historiadores. Esta práctica disciplinaria la podrá trasmitir a los estudiantes de educación media y básica.

La práctica disciplinaria va a generar un nivel de exigencia y formación que fortalezca y consolide en términos científicos la actividad docente con los conocimientos de investigación, que pueden ser mucho más ampliadas si se desarrolla en los colegios, para medir percepciones de la comunidad escolar sobre la historia reciente. Este efecto provocará no solo un Profesor Innovador y Descubridor en base a la investigación, sino también un Estudiante Descubridor de nuevos conocimientos de la historia.

\section{REFERENCIAS BIBLIOGRÁFICAS}

Almeyda, L., Milos, P. y Whipple, P. (2007). Historia y Ciencias Sociales. Texto de estudio. Santiago de Chile: Editorial Mare Nostrum.

Bordieu, P. (2002). Lección sobre la Lección. Barcelona: Anagrama.

Carvallo, A. (1992). Los Hombres de la Transición. Santiago: Andrés Bello.

Corvalán, L. (1997). De lo vivido y lo peleado. Memorias. Santiago: LOM.

Fernández, S. (1994). Mi lucha por la democracia. Santiago: Los Andes.

Landreau, G. (1988). Diálogo sobre la Historia. Madrid: Alianza.

Nietzsche, F. (1945) De la utilidad y de los inconvenientes de los estudios históricos para la vida. Buenos Aires: Ediciones Bajel.

Habermas, J. (2001). Identidades Nacionales y Postnacionales. Barcelona: Paídos.

Hobsbawm, E. (2002). Sobre la historia. Barcelona: Editorial Crítica.

Stern, S. (2000). De la memoria suelta a la memoria emblemática: hacia el recordar y el olvidar como proceso histórico (Chile 1973-1998). En Mario Garcés \& Pedro Milos (Comps.), Memorias para un Nuevo Siglo. Santiago: Lom.

Touraine, A. (1999). Crítica a la Modernidad. Barcelona: Crítica.

\section{FUENTES HEMEROGRÁFICAS}

El Metropolitano. Sección Reportajes. Santiago de Chile. 12/10/1999.

El País. España. 2/11/2003. 
